\title{
Biomarkers in Mild Stages of Alzheimer's disease: Utility in clinical practice and their relation with nutritional and lifestyle factors
}

\author{
Carol Dillon $^{1,2,3}$, Patricio Pérez Leguizamon ${ }^{1}$; Silvina Heisecke ${ }^{1,2,3}$, Diego M. Castro ${ }^{1}$, \\ Jorge Lopez Camelo ${ }^{2,3}$; Leandro Lon ${ }^{1}$, Cecilia M. Serrano ${ }^{1}$, Veronica Guelar ${ }^{1}$, and \\ Fernando E. Taragano, ${ }^{1,2,3}$
}

${ }^{1}$ SIREN, Research and Rehabilitation Subsection for Neurocognitive Diseases, Neurology Section, Department of Medicine CEMIC, CEMIC University Hospital, Buenos Aires, Argentina; ${ }^{2}$ Research Unit CEMIC-CONICET, Buenos Aires, Argentina; ${ }^{3}$ National Council of Scientific and Technical Research (CONICET), Buenos Aires, Argentina

Corresponding author: Carol Dillon, MD, PhD, CEMIC University Hospital, Avenida Galván 4089 (1431FWO), Buenos Aires, Argentina

Submission Date: September 11, 2016, Accepted Date: October 25, 2016, Publication Date: October 30, 2016

Citation: Dillon C., Leguizamon P.P., Heisecke S., Castro D.M., Camelo J.L., Lon L, Serrano C.M., Guelar V., and Taragano F.E. Biomarkers in Mild Stages of Alzheimer's disease: Utility in clinical practice and their relation with nutritional and lifestyle factors. Functional Foods in Health and Disease 2016; 6(10):627-649

\begin{abstract}
Background: The use of biomarkers in basic and clinical research as well as in clinical practice has become so common that their presence as primary endpoints in clinical trials is now accepted. A biomarker refers to a broad subcategory of medical signs. The aims of this article are to consider the of use biomarkers in Mild stages of Alzheimer's disease (AD) in research and clinical settings, in addition to defining their utility in clinical practice relating this with nutritional and lifestyle factors as possible treatment.
\end{abstract}

Methods: We searched MEDLINE, PubMed, and AgeLine databases using different keywords.

Conclusions: A summary of the utility of biomarkers in AD and nutritional and lifestyle factors used as treatment in mild stages are described.

Key words: Biomarkers, Alzheimer's disease, Dementia, Utility, Clinical practice, Nutritional and Lifestyle Factors, Early treatment 


\section{BACKGROUND}

The use of biomarkers in basic and clinical research, as well as in clinical practice, has become so common that their presence as primary endpoints in clinical trials is now accepted.

Biomarkers are parameters (physiological, biochemical, anatomic) that can be measured in vivo and reflect specific features of disease-related pathophysiological processes. They stand for medical signs observed from outside the patient that can be measured accurately and reproducibly. This includes neuropsychiatric tests, neuropsychological batteries, laboratory tests, neuroimaging studies, genetic test, etc. [1].

Alzheimer's disease (AD), accounts for $60 \%$ to $70 \%$ of cases of dementia [1,2]. AD is a progressive neurodegenerative disease that is characterized by impairment of cognitive and functional abilities as well as by neuropsychiatric symptoms (NPS). Cognitive impairment can include impairment of memory, visuospatial functions, language, and executive functions [1-3]. Additionally, NPS such as depression, apathy, and agitation appear to be symptoms already common in the early stages of $\mathrm{AD}$ and can have an impact on the well-being of both patients and caregivers $[4,5]$. Cognitive performance has been consistently associated with functional ability [6].

The cause of Alzheimer's disease is poorly understood [7]. About 70\% of the risk is believed to be genetic, with many genes usually being involved. Some of them predispose (APOE in late onset) and some are involucrated (amyloid precursor protein (APP) on chromosome 21, the gene presenilin-1 (PS-1) on chromosome 14 and the presenilin gene 2 (PS2) in early onset or familiar type) in the development of $\mathrm{AD}$ [8], while other genes act as protector factors [9].

Moreover, there are clinical risk factors which include a history of head injuries, depression, or hypertension [7], dyslipemia, cigarrette smoking, sedentarism, obesity, and diabetes. In fact, the data which demonstrated that $\mathrm{AD}$ may have vascular modifiable risk factors came from studies on cardiovascular conditions and diabetes [10].

The disease process is associated with the deposit of amyloid plaques and tangles in the brain [8]. A probable diagnosis is based on the history of the illness and cognitive testing with medical imaging and blood tests to rule out other possible causes [8].

Several biomarkers are used in clinical practice for the detection of mild stages of AD in order to implement different treatments to ameliorate the conversion to dementia. Prevention of vascular risk factors by implementing lifestyle changes in nutrition, promoting aerobic exercise $[11,12]$, diminishing stress, and treating depression are important for this matter. Moreover, cognitive stimulation and social interaction are also key factors in the treatment of mild stages [13].

Aims: The aims of this article are:

1) To consider the use of biomarkers in mild stages of Alzheimer's Disease (AD) in research and clinical settings

2) To define their utility in clinical practice

3) To relate this with nutritional and lifestyle factors as possible treatments 
Searching strategy: We searched MEDLINE, Pubmed, and AgeLine databases using the keywords "Biomarkers", "Alzheimer's disease", "Complementary methods", "Neuropsychological test in Alzheimer's Disease", "Neuroimaging in dementia", "Genetics in Alzheimer's disease". We focused on research studies and review papers. We selected articles published in Spanish and English language.

We also selected papers published in different international journals that were related to research studies developed by our research group.

Biomarkers used in Research and Clinical Settings: The evaluation of an elderly patient consulting for cognitive impairment and/or neuropsychiatric symptoms (NPS) should begin with a complete history of cognitive and functional status, co-morbidities, family history, prescribed and non-prescribed medications, sleep patterns, and concerns regarding social and environmental changes.

Detailed neuropsychiatric and medical examinations should be conducted to evaluate concomitant or triggering clinical intercurrences.

Neuropsychiatric markers: Validated instruments, both general scales and focused scales, can be used to determine the presence, intensity, or frequency of NPS in patients with mild cognitive impairment (MCI) and dementia. General scales allow a broad spectrum of NPS to be assessed, while focused scales are used to assess one or more behavioral symptoms (for example, scales for depression or agitation) [3].

General scales are used to conduct multidimensional examinations, and include the Behavioral Pathology in Alzheimer's Disease Rating Scale (BEHAVE-AD), [14] the Neurobehavioral Rating Scale (NRS) [15], the Behavioral Rating Scale for Dementia (BRSD) [16], and the Neuropsychiatric Inventory (NPI) [17].

The NPI is the most widely used scale to measure NPS associated with cognitive disorders. It is a fully structured interview, which obtains data from an informant, usually from the patient's caregiver. Recently, the NPI - Clinician (NPI-C) was developed [18]. The revised NPI-C can be used to assess single or multiple domains [19]. Unlike the NPI, each domain and potentially each sub-question within a domain, can be rated on the NPI-C. Caregivers and patients rate the frequency, severity, and distress of each item. Then, the clinician provides an overall rating based on interviews and additional chart information, which brings additional strength to the measure compared with the original scale.

The NPI-C was field tested in an international validation study and compared with focused scales to determine behavioral symptoms in cognitive disorders convergent validity. It was trimmed to 142 items (61 more than the NPI) and has been translated to several European languages [19].

Focused scales are instruments that are used to conduct uni-dimensional evaluations, including the Hamilton Depression Rating Scale [20], the Cornell Scale for Depression in Dementia [21], the Geriatric Depression Scale [22], or the Cohen-Mansfield Agitation Inventory [23]. 
Neuropsychological markers: Individuals who will develop AD present with specific cognitive difficulties several years before any clinical sign of pathology is detected [24, 25]. Typically, memory is the most common domain involved among patients in preclinical stage of AD [25]. In fact, amnestic forms of MCI have been considered as the most prominent subgroup with the highest rate of conversion to $\mathrm{AD}$, while the non-amnestic forms are seen as those which most frequently progress to a non-AD dementia [26, 27].

In this regard, studies have identified decline in episodic memory (i.e., the ability to learn and retain new information) as the earliest and most salient manifestation of typical AD [24, 25, 28] and this impairment is generally considered as a core requirement for MCI due to AD [29]. Episodic memory tests, that are useful for identifying those MCI patients who have a high likelihood of progressing to AD dementia, share the same characteristic in that they assess both immediate and delayed recall; thus, it is possible to determine retention over a delay. Many of the tests that have proven to be useful in this way are word-list learning tests with multiple trials [2].

Since recall deficits can be caused by different conditions from AD (e.g., depression, or frontotemporal lobar degeneration), the Research Diagnostic Criteria proposed for the Diagnosis of $\mathrm{AD}$ suggested a more specific memory signature as the core clinical symptom of $\mathrm{AD}$, which consists of a recall deficit which does not improve with cueing [26, 27]. Moreover, evidence has proved that clued recall deficits are associated with a progression of atrophy that closely parallels the spatiotemporal distribution of neurofibrillary degeneration in early AD. A recent prospective volumetric brain study has revealed that patients with impaired free recall but normal total recall (high index of cueing) on the Free and Cued Selective Recall Reminding Test (FCSRT) developed subcortical and frontal grey matter loss, while patients with impaired free and total recall (low index of cueing) developed grey matter atrophy within the left anterior and lateral temporal lobe [31].

A recent research has found that deficits in binding test can also be a marker for the early detection of $\mathrm{AD}$ [32].

We cannot fail to consider the importance of examining domains in addition to memory, and to also be aware of the possibility that atypical clinical presentations of AD may arise and need to be recognized [2] .

Differential profiles of cognitive impairment are described in Table 1 [33].

Laboratory Tests: Proper evaluation of patients with mild cognitive impairment and dementia should include studies of blood pressure, heart function, blood variables, and inflammatory conditions.

A routine that includes a complete blood count, erythrocyte sedimentation rate, urea, glucose, electrolytes, liver function and cholesterol is also mandatory.

In populations at risk, serum studies should be completed as VDRL and FTA-ABS, and HIV to rule out differential diagnosis. To study possible dislipemias, a lipid panel is necessary. If there are nutritional problems or the patient has neuropathy, myelopathy or anemia, laboratory tests should be completed with the dosage of B12 and folic acid. Other tests that should be included are thyroid function tests. 
Table 1. Cognitive impairment differential profiles ${ }^{1}$

\begin{tabular}{|c|c|c|c|c|}
\hline & $\begin{array}{l}\text { Posterior } \\
\text { cortical } \\
\text { dementia }\end{array}$ & $\begin{array}{l}\text { Anterior } \\
\text { cortical } \\
\text { dementia }\end{array}$ & $\begin{array}{l}\text { Dysexecutive } \\
\text { subcortical } \\
\text { dementia }\end{array}$ & $\begin{array}{l}\text { Attentional } \\
\text { subcortical } \\
\text { dementia }\end{array}$ \\
\hline Disease & $\begin{array}{l}\text { Alzheimer's } \\
\text { type dementia }\end{array}$ & $\begin{array}{l}\text { Frontotemporal } \\
\text { dementia }\end{array}$ & $\begin{array}{lr}\text { Vascular } & \text { dementia } \\
\text { small } & \text { vessel } \\
\text { disease } & \\
\end{array}$ & Depression \\
\hline \multicolumn{5}{|l|}{ Cognition task } \\
\hline Language & $\begin{array}{l}\text { Semantic } \\
\text { anomia }\end{array}$ & $\begin{array}{l}\text { Evocation } \\
\text { anomia }\end{array}$ & Conserved & Conserved \\
\hline Speech & Conserved & Conserved & $\begin{array}{l}\text { Dysarthria and } \\
\text { hypophonia }\end{array}$ & Slowed \\
\hline Episodic memory & $\begin{array}{l}\text { Amnesia - } \\
\text { storage deficit }\end{array}$ & $\begin{array}{l}\text { Memory loss - } \\
\text { retrieval deficit }\end{array}$ & $\begin{array}{l}\text { Memory loss - } \\
\text { retrieval deficit }\end{array}$ & $\begin{array}{l}\text { Memory loss - } \\
\text { retrieval deficit }\end{array}$ \\
\hline $\begin{array}{l}\text { Semantic } \\
\text { memory }\end{array}$ & $\begin{array}{l}\text { Early } \\
\text { alteration } \\
\text { semantic } \\
\text { anomia }\end{array}$ & Conserved & Conserved & Conserved \\
\hline $\begin{array}{l}\text { Procedural } \\
\text { memory }\end{array}$ & Late alteration & Early alteration & Early alteration & Conserved \\
\hline Attention & Conserved & Conserved & Conserved & Altered \\
\hline $\begin{array}{l}\text { Visuospatial } \\
\text { skills }\end{array}$ & Altered & $\begin{array}{l}\text { Conserved - } \\
\text { Except planning } \\
\text { failures }\end{array}$ & $\begin{array}{l}\text { Conserved - } \\
\text { Except planning } \\
\text { failures }\end{array}$ & Conserved \\
\hline Calculation & Altered & Conserved & Conserved & Conserved \\
\hline Executive skills & Late alteration & $\begin{array}{l}\text { Early } \\
\text { alteration }\end{array}$ & Early alteration & Early alteration \\
\hline Social skills & Late alteration & $\begin{array}{l}\text { Early } \\
\text { alteration }\end{array}$ & Conserved & Conserved \\
\hline \multicolumn{5}{|l|}{ Behavior task } \\
\hline Disinhibition & Late & $\begin{array}{l}\text { Early and } \\
\text { remarkable }\end{array}$ & Variable & Late \\
\hline Psychotic traits & Late & Rare and late & Variable & Frequent \\
\hline Emotion & $\begin{array}{l}\text { Apathy and } \\
\text { depression }\end{array}$ & Severe apathy & Apathy & Depression \\
\hline Motor skills & Conserved & Conserved & $\begin{array}{l}\text { Pyramidal and } \\
\text { extrapyramidal } \\
\text { signs }\end{array}$ & Conserved \\
\hline
\end{tabular}

${ }^{1}$ Translated with permission from Dillon C, Allegri RF. Vertex 2010 May-Jun;21(91):301-13 [33] 
Specific Laboratory Tests for AD: For a long time, diagnosis of Alzheimer's disease has relied largely on documenting mental decline, identifying dementia, and confirming the disease through postmortem anatomopathological findings. However, researchers have worked hard to discover an easier and more accurate way to detect AD before its devastating symptoms begin. Nowadays, it is well established that AD has already caused severe brain damage in individuals who are diagnosed in this documentary way, mainly due to accumulation of neurofibrillary tangles and amyloid plaques [1,2].

Intracellular neurofibrillary tangles are formed due to hyperphosphorylation and oligomerization of tau, a microtubule-associated protein mainly present in axons. Extracellular amyloid plaques are formed from b-amyloid protein peptides (Ab), which are fragments formed by cleavage of an APP present in cellular membranes. APP can be processed by alfa-and gamma-secretases, generating a non-amyloidogenic product, or by beta- and gamma-secretases, generating $\mathrm{Ab}$ peptides, which are amyloidogenic and are prone to form plaques [34].

In the study developed by Braak and Braak, in which they studied eighty three brains of autopsy from non-demented and demented individuals, they found out that distribution pattern and packing density of amyloid deposits turned out to be of limited significance for differentiation of neuropathological stages [35]. Additionally, they observed the intraneuronal accumulation of insoluble abnormal phosphorilated tau proteins. Neurofibrillary tangles and neuropil threads exhibited a characteristic distribution pattern permitting the differentiation of six stages [35].

Animal models have greatly contributed to elucidate different aspects of the disease's pathogenesis [36]. Data generated using genetically modified mice support the "amyloid cascade theory" explaining that the accumulation of $\mathrm{Ab}$ is the initial pathophysiological event in $\mathrm{AD}$, leading to tau aggregation, synaptic loss, and cell death [36]. Mice models overexpressing APP display progressive $\mathrm{Ab}$ deposition in diffuse pattern and neuritic plaques, cerebral amyloid angiopathy, astrocytosis, microgliosis, mild hippocampal atrophy, neurotransmission changes, and cognitive and behavioral deficits [37].

Levels of total tau, phosphorylated tau at threonine 181 and $B$-amyloid 1-42 (Aß42) determined in cerebrospinal fluid have become well-established AD biomarkers [38], and their profiles have been proposed to predict the course and the outcome of persons with amnestic mild cognitive impairment [39].

Many studies of patients with MCI have demonstrated that abnormal baseline levels of cerebrospinal fluid (CSF) total tau (T-tau), phosphorylated tau at threonine 181 (P-tau), and A42 are associated with subsequent conversion to AD dementia [40-49]. However, these previous studies [40-43; 46-49] have had short clinical follow-up of 1 to 3 years, except for 2 studies [44, 45] with follow-up of 4 to 5 years. Given that AD is a slowly progressive disorder, it probably takes at least 10 years before most patients with prodromal AD develop dementia and can be diagnosed as having clinical AD.

The study by Hansson et al [44], with a median clinical follow-up of 5.2 years, is still the most extensive follow-up of a cohort of patients with MCI at baseline in which the diagnostic accuracy of biomarkers for prodromal AD has been studied [50]. 
Neuroimaging studies: The development of three-dimensional imaging techniques has substantially improved the chances of neurological diagnosis. While computed tomography (CT) and magnetic resonance image (MRI) are routinely used for the detection of brain morphological lesions; neuroimaging through the Positron radiotracers as single photon emission (SPECTsingle photon emission tomography) and positron emission tomography (PET-positron emission tomography) allow us to access the functionality of certain brain areas, by measuring blood flow (SPECT), or metabolism (PET). This is obtained from the morphology to study the function, opening an endless range of possibilities in cognitive impairments and dementia.

Neuroimagining biomarkers are valuable diagnostic and prognostic tools for AD. These biomarkers provide evidence of downstream brain changes that correlate with regional distribution of Alzheimer's pathology, including regional brain atrophy seen by structural techniques and regional glucose hypometabolism or hypoperfusion detected with functional techniques $[2,30]$.

Structural imaging techniques: The main structural imaging techniques used are CT and MRI. In $\mathrm{AD}$, the CT may reveal diffuse cerebral atrophy with enlargement of the cortical sulci and increased size of ventricles. However, these are late changes, so CT does not have any role in the early diagnosis of AD [51]. Therefore, the principal utility of the CT is limited to rule out any potentially treatable cause of dementia (e.g. tumour or subdural haematoma) and to evaluate the presence and extent of cerebrovascular disease [52].

Conversely, MRI is currently the imaging modality of choice for assessing subjects with suspected dementia [52]. Indeed, a characteristic pattern of brain atrophy involving the medial temporal lobes, paralimbic and temporoparietal cortices is considered a biomarker of AD-related neurodegeneration [53]. Hipoccampal atrophy is the best established and validated MRI marker of $A D$ [54]. Significant atrophy of the hippocampal formation can be demonstrated by MRI even in preclinical stages of $\mathrm{AD}$ and it predicts later conversion to $\mathrm{AD}$ with about $80 \%$ accuracy. Likewise, hippocampal volume is a potential structural marker of disease progression [55]. Regarding their limitations, structural MRI measures are not as specific to AD as amyloid measurements and may include effects of aging and other neurodegenerative diseases and processes. Among its benefits are its ease of use, non-invasiveness, and relatively low cost (compared with PET) [56].

Memory impairment is an early manifestation of Alzheimer's disease (AD). The structures most involved in the pathology, including the early stage are: the hippocampal formation and parahippocampal rotation. A reduction in the volume of these structures has proven to be predictive of $\mathrm{AD}[57,58]$. The atrophy in this region correlates with neuropsychological performance of $\mathrm{AD}$ [59]: performance on verbal tests correlates with the volume of the left medial temporal lobe, in addition to nonverbal tests with the volume of the right medial temporal lobe. Golebiowski et al and Frisoni et al described high sensitivity and specificity of the medial temporal lobe volume in $\mathrm{AD}[60,61]$.

Pantel et al revealed that the corpus callosum atrophy in $\mathrm{AD}$ is probably cause a syndrome of cortico-cortical disconnection that contributes to the severity of dementia [62]. 
In contrast to normal aging, the hippocampus is atrophied in the early stages of $\mathrm{AD}$, making it a perfect candidate to be a diagnostic marker. Maximum neuronal loss in hippocampal formation occurs in the CA1, subiculum region and entorhinal cortex [63]. In patients with more than four years illness course, loss of volume in the anterior cingulate was the most sensitive to discriminate $\mathrm{AD}$ patients from normal controls measure. Other structures with significant sensitivity in the later stages of $\mathrm{AD}$ include the lower and medial temporal lobe, the basal ganglia and the amygdale [63].

Moreover, parietal atrophy (precuneos) is also an anatomical sign of probable AD.

Functional imaging techniques: Functional neuroimaging studies detect changes in perfusion and metabolism well before brain atrophy can become apparent in structural neuroimaging studies.

SPECT is one of the neurophysiological studies that measures cerebral perfusion while PET with fluorodeoxyglucose measures neuronal metabolism; labeled Oxigen ${ }^{15}$ water measures perfusion and helps doing activation studies.

$\mathrm{AD}$ has a characteristic progression. According to the pathological stages of Braak and Braak [35], it begins with the deposition of neuritic plaques in hippocampal CA1, subiculum and entorhinal cortex, and then progresses to the rest of the crust subsequent association (parietal, temporal and posterior cingulate). Thus, the onset of the disease is characterized by loss of episodic memory with difficulty learning new information, which correlates with the first stage of Braak and Braak, then the visual-spatial and semantic aspects disorders and Language processing subsequent association cortex are added. These changes can be detected with functional neuroimaging studies of SPECT and PET. PET has greater spatial resolution and therefore, it is possible to detect the hypometabolism in medial temporal cortex (hippocampal and parahippocampal).

SPECT is a method to determine changes in regional cerebral blood flow at rest, through a radioisotope (Technetium 99) and a vehicle such as HMPAO or ECD. The changes in blood flow are more precocious than the structural changes detected by CT or MRI, so it is useful to see the pattern of changes in the various dementias. $\mathrm{AD}$ is recognized by temporal and bilateral posterior parietal hypoperfusion [64].

Dementia associated with psychiatric symptoms add alterations to SPEC; for example, a patient with Alzheimer's disease and apathy will have temporoparietal hypoperfusion added with hipoferfusion in medial prefrontal and anterior cingulate cortex [65].

Regarding the use of the neurophysiological studies investigating early detection and progression of dementia, tracking longitudinal studies found that normal subjects who developed mild cognitive impairment showed temporomedial hypometabolism measured by (fluorodeoxyglucose) FDG PET up to three years before it could be clinically detected [63]. Activation studies with PET and Oxigen15 labeled water, in addition to functional MRI studies demonstrated that, for a given cognitive task, patients with cognitive impairment activated older brain areas compared to controls. This finding is interpreted as a compensatory mechanism where patients should activate more brain areas to achieve the same performance as controls [66]. However, when atrophy progresses and the patient can no longer perform the cognitive task, a lack of activation of involved brain areas is observed [67]. 
We cannot fail to mention other methods recently developed as tractography or image voltage-diffusion (it allows an MRI study observe the paths of the great white tracts like the corpus callosum, cingulate, the internal capsule and the superior longitudinal fasciculus) where patients with Alzheimer's disease show atrophy tracts of associative linking areas, however not in the internal capsule [68].

Moreover, studies of diffusion-perfusion MRI are used to differentiate the new cerebral infarcts from the old ones. There is also research and development of new radioligands for viewing amlyliod deposits and enzyme activity with PET [69].

PET and SPECT are the main functional neuroimaging techniques used in AD. These techniques detect changes in regional metabolism and regional perfusion in the brain, respectively. PET with 18F-2fluoro-2-deoxy-D-glucose (FDG-PET) in AD shows a pattern of glucose hypometabolism involving temporoparietal, posterior cingulate and precuneus cortices [70-72]. On SPECT examinations, patients with $\mathrm{AD}$ show temporal and parietal lobe hypoperfusion $[73,74]$. In a recent study comparing the relative diagnostic accuracy of both techniques for the diagnosis of degenerative dementia (AD and dementia with Lewy bodies) [75], FDG-PET was superior to SPECT, with a sensitivity and specificity of $85 \%$ and $90 \%$ respectively, for FDG-PET and $71 \%$ and $70 \%$ respectively, for SPECT.

Regarding early diagnosis of $\mathrm{AD}$, in a prospective, community based study [76], the sensitivity and specificity of FDG-PET was $78 \%$ and $81 \%$ respectively, for the diagnosis of early-stage AD. Furthermore, FDG-PET predicts progression from MCI to dementia with high sensitivity and specificity $[77,78]$.

As mentioned above for structural imaging techniques, these functional imaging are also neuronal injury markers and not specific for $\mathrm{AD}[2,30]$. Nonetheless, neuroimaging measures are considered valuable markers to monitor disease progression, to characterize the clinical phenotype in atypical $\mathrm{AD}$ [30], and to differentiate $\mathrm{AD}$ from other neurodegenerative diseases [51].

Beta amiloid imaging: Molecular neuroimaging techniques have made it possible to visualize human brain amyloid $\beta(A \beta)$ deposition during life using PET. Currently, several amyloid tracers are in use in $\mathrm{AD}$ research, including carbon-11 Pittsburgh compound $\mathrm{B}$ (PiB) [79],18Fflutemetamol (18F-PiB derivate) [80], Florbetapir F 18 (18F-AV-45) [81], Florbetaben (BAY 94-9172) [82]. These ligands have shown high specificity correlating with neuritic plaques in post-mortem studies [81, 83] and biopsy studies [84]. Thus, Amyloid PET is considered a specific biomarker of AD [30].

Regarding the value of amyloid PET in the early diagnosis of $\mathrm{AD}$, a recent study that included 426 subjects [85], concluded that in a longitudinal analysis $A \beta$ deposition (but not hypometabolism) was associated with ongoing cognitive decline in normal subjects, suggesting that in normal older individuals, amyloid is closely linked to the earliest indications of clinical decline. Additionally, in patients with MCI amyloid PET might be a valuable tool for predicting progression to dementia [86, 87]. The Imaging Task Force, the Society of Nuclear Medicine and Molecular Imaging, and the Alzheimer's Association have reviewed the indications for amyloid PET and have developed the following criteria for its use [88]. 
Amyloid imaging is appropriate in the situations listed here for individuals with all of the following characteristics:

1. Patients with persistent or progressive unexplained MCI

2. Patients satisfying core clinical criteria for possible $\mathrm{AD}$ because of unclear clinical presentation, either an atypical clinical course or an etiologically mixed presentation

3. Patients with progressive dementia and atypically early age of onset (usually defined as 65 years or less in age)

Amyloid imaging is inappropriate in the following situations:

1. Patients with core clinical criteria for probable AD with typical age of onset

2. To determine dementia severity

3. Based solely on a positive family history of dementia or presence of apolipoprotein $E$ (APOE) $\varepsilon 4$

4. Patients with a cognitive complaint that is unconfirmed on clinical examination

5. In lieu of genotyping for suspected autosomal mutation carriers

6. In asymptomatic individuals

7. Nonmedical use (e.g., legal, insurance coverage, or employment screening)

8. Discussion of individual indications

Genetic studies: Other biological markers used are the genetic studies. The early onset of the disease is related to three genes: the APP on chromosome 21, the PS-1 gene on chromosome 14, and the PS-2 16. No chromosome exist in epidemiological studies on the subject but mutations in these genes seem to explain only half of early-onset AD. There are probably more genes involved. New predictive and diagnostic testing these AD early genes could be useful in diagnosis and genetic counseling for the family [88].

The gene for apolipoprotein E (APOE) located on chromosome 19 has three alleles E2, E3 and E4 [88]. The presence of the allele E4 / E4 is associated with an earlier onset of the disease $[89,90]$. The partnership between AD and apo E4 has been confirmed in various ethnic groups [91]. However, because the APOE gene is not a deterministic gene but a gene for susceptibility or risk factor, its role in clinical practice is not yet clearly defined. It could be of interest to use as a complement to other tests in the diagnosis of $\mathrm{AD}$, but not advised for determining whether an individual is a carrier presymptomatic AD.

There are sporadic forms and genetic forms of $\mathrm{AD}$, usually early onset. 10-15\% of $\mathrm{AD}$ cases correspond to familial forms [92-93]. The first-degree relatives of patients with $\mathrm{AD}$ have increased 2-4 times the personal risk of developing the disease [92-93]. In a small group of families, there is an autosomal dominant AD transmittance, which manifests in middle age [9293]. To date, there are three identified genes responsible for early-onset familial forms; on chromosome 21, 14, and 1. For familial forms of AD it has been reported late ligament to chromosome 12 but the gene is not cloned [93].

The APOE confers susceptibility to both sporadic and late EA family. APOE gene on chromosome 19 has three alleles 2, 3, and 4. In the general population, the presence of the APOE genotype 4 is associated with an increased risk of AD. However, the sensitivity (about 50\%) and 
specificity (about 75\%) for the presence of the APOE genotype 4 in the diagnosis of AD, is insufficient to guide diagnosis or quantify accurately the genetic risk [94, 95].

Cathepsin D (CATD) is an intracellular acidic protease that cleaves the amyloid beta precursor protein (APP-B). An allelic variant of that enzyme, CATD * $\mathrm{T}$, is related to the degenerative process of AD through the excision of the B-amyloidogenic APP components. Allele carriers CATD * T have a 3.1 times increase in the risk of developing AD. If a patient has two alleles, the APOE-4 and T* CATD, the risk of AD is increased 19 times [96].

Jonsson et al studied coding variants in APP in a set of whole-genome sequence data from 1,795 Icelanders. They found a coding mutation (A673T) in the APP gene that protects against Alzheimer's disease and cognitive decline in the elderly without Alzheimer's disease [9].

The place of genetic testing and genetic risk assessment remains unclear. Genetic testing in the dementing diseases of the elderly is an underdeveloped field.

Although no effective prevention or treatment measures are available today, it is agreed that early diagnosis (including Genetic Testing - GT) of the disease should be emphasized [97].

However, given the enormous advances in this area, GT for the diagnosis of AD will become available in the near future to millions of individuals who are at risk of developing the disease and an increasing amount of research is being devoted to this topic in the last years.

Atypical presentations of Alzheimer's Disease: Alzheimer disease (AD) is the most common cause of dementia. The cardinal manifestation of AD is progressive loss of memory. However, there are some non-amnestic presentations of AD, also called atypical AD. Symptoms of AD can sometimes start suddenly. In the presence of atypical symptoms or sudden onset, it may be difficult to distinguish $\mathrm{AD}$ from other dementias. Posterior cortical atrophy (PCA) is a neurodegenerative syndrome characterized by striking progressive visual impairment and a pattern of atrophy mainly involving posterior cortices. PCA is the most frequent atypical presentation of Alzheimer disease. Signal characteristic features of the PCA syndrome are: the early onset, focal loss of visual perception and focal posterior brain atrophy [98]. Cases of Primary Progressive Aphasia, like semantic dementia (SD) with the initial complaint of forgetfulness can diagnose as AD [99].

Primary progressive aphasia (PPA) is caused by selective neurodegeneration of the language-dominant cerebral hemisphere; a language deficit initially arises, as the only consequential impairment and remains predominant throughout most of the course of the disease [100].

Agrammatic, logopenic and semantic subtypes, each reflecting a characteristic pattern of language impairment and corresponding anatomical distribution of cortical atrophy, represent the most frequent presentations of PPA. The underlying neuropathology of PPA is, most commonly, frontotemporal lobar degeneration in the agrammatic and semantic forms, and Alzheimer disease (AD) pathology in the logopenic form; the AD pathology often displays atypical and asymmetrical anatomical features consistent with the aphasic phenotype. The PPA syndrome reflects complex interactions between disease-specific neuropathological features and patientspecific vulnerability [101]. 
A careful clinical history, a detailed mental evaluation, and neuroimaging will overcome this difficulty in diagnosis.

Utility of Biomarkers in Clinical Practice: Biomarkers are useful in clinical practice for:

1) Helping physicians to diagnose patients in early phases.

2) The determination of differential diagnosis.

3) Establishing guidelines for researchers and clinicians to communicate securely and efficiently diagnosing preclinical AD.

4) The establishment of a process that effectively translates this diagnosis in clinical practice and health policy.

5) The adaptation of the laws, regulations and professional practices for the diagnosis of preclinical AD.

Among the causes that lead patients to want these types of studies performed are the following:

1) The ability to better plan their future.

2) The possibility to adopt changes that are focused on improving the quality of life.

3) The practice of cognitive stimulation, physical activity, control of cardiovascular risk factors, eating a proper diet as preventive interventions [102].

Nutritional and Lifestyle factors: The importance of early diagnosis in AD is to try to reduce the conversion to dementia, the clinical stage where the patient starts depending on caregivers and has lost independence, something crucial in a human being's life.

Biomarkers nowadays, help clinicians to make earlier diagnosis and therefore to implement certain therapies to cope with the symptoms.

Over the past decade, there has been increasing focus on the influence of a number of lifestyle factors; including: intellectual engagement, social interaction, nutrition, and physical activity; on the cognitive vitality of older adults. Some studies have examined changes in cognition within the normal range, whereas others have asked whether lifestyle factors reduce the risk or delay the onset of age-associated diseases such as Alzheimer's, Cerebrovascular Disease, or Depression. Physical activity in midlife seems to protect from dementia in old age. Leisure-time physical activity (LTPA) is particularly important due to its broader effects in general and cardiovascular health [103].

Moreover, other lifestyle factors as nutritional components or changes in dietary recipes are also important in mild stages.

More than two decades of research on nutritional risk factors for dementia has yielded promising, but not yet definitive, findings of the foods and nutrients to either include or avoid in one's diet to prevent dementia [104].

Crichton GE, Elias MF and Akerwi A, investigated whether chocolate intake was associated with cognitive function, with adjustment for cardiovascular, lifestyle and dietary factors. Authors concluded that chocolate intake was positively associated with cognitive performance, across a range of cognitive domains in a dementia free community-dwelling population. The associations between more frequent weekly chocolate consumption and cognitive performance remained 
significant after adjustment for a number of cardiovascular risk factors, including total and LDLcholesterol, glucose levels, and hypertension. Associations were not attenuated with the addition of dietary variables (alcohol, meats, vegetables, and dairy foods), suggesting that chocolate may be associated with cognition irrespective of other dietary habits [105].

Other research studies have supported the action of the methylxanthinesin chocolate, caffeine and theobromine, in relation to cognitive function. Coffee is consumed by millions of individuals from all over the world, possibly in part, due to its caffeine content. It is the best known psychoactive stimulant acting to improve short-term alertness and arousal [106, 107]. Longer-term, population based studies have provided evidence that long-term caffeine intake may offer some protection against cognitive decline [108].

Moreover, epidemiological and animal studies have provided research data on which to consider the neuroprotective effects of individual nutrients, including vitamin E, B vitamins, and the n-3 fatty acid docosahexaenoic acid [109]. Positive associations were observed for vegetables (especially green leafy vegetables, which are good sources of folate, vitamin E, and carotenoids), seafood (a source of n-3 fatty acids), and berries (a source of polyphenols) [110].

More limited data are available on the neuroprotective benefits of monounsaturated fat, carotenoids, polyphenols, and vitamin D. Diets high in saturated and trans fats have been shown to increase cognitive decline and the risk of developing dementia, 2 and deleterious effects have been suggested for excessive intake of iron,3 copper (in conjunction with high saturated fat diets), 4 and synthetic folate or folic acid, among individuals with low vitamin B12 status [110112].

Most of the epidemiological studies of dietary patterns have investigated the Mediterranean diet, and only four [113-116] of the 10 informative studies on this diet have found clear protective effects against cognitive decline or dementia [113-119].

It is evident that nutrients in foods exert differential effects on the brain.

As has been repeatedly demonstrated, isolating these nutrients and foods enables the formation of dietary interventions to optimize neuropsychological health. Adopting dietary patterns to delay or slow the onset of cognitive decline is an appropriate avenue, given the limited treatments available for dementia [120].

There are three medical foods that claim to offer symptomatic benefits: Axona®, Souvenaid ${ }^{\circledR}$ and CerefolinNAC®. Axona supplies ketone bodies as alternative energy source to neurons. Souvenaid provides precursors thought to enhance synaptic function. CerefolinNAC addresses the role of oxidative stress related to memory loss [121].

The characteristic of a medical food is that it is expected to be used under the regular care of a physician, so patients who are interested in using this type of material should discuss it carefully with their own physician and make sure that they, the physician, and the family understand appropriate use, realistic treatment expectations, and potential adverse effects [121].

\section{CONCLUSIONS:}

After describing the different biomarkers that can be used for the diagnosis of mild stages of AD and explaining their utility both in research settings and clinical practice, we intended to relate this with the implementation of different nutritional and lifestyle changes. The aim of the 
implementation of this type of treatment is try to reduce the vascular risk factors that can influence the conversion to dementia and to improve the patient's quality of life in mild stages of the disease.

However, all the data obtained by the use of new and more specific biomarkers has to be indicated following scientific and clinical criteria. These biomarkers in clinical practice could impact costs and the incidence of incidental findings, which could be a concern. Thus, this matter has to be considered, since presently there is not a disease modification treatment, and lifestyle changes are a global recommendation for the overall population.

Abbreviations: Alzheimer's Disease (AD), neuropsychiatric symptoms (NPS), amyloid precursor protein (APP), gene presenilin-1 (PS-1), presenilin gene 2 (PS-2), mild cognitive impairment (MCI), Behavioral Pathology in Alzheimer's Disease Rating Scale (BEHAVE-AD), Neurobehavioral Rating Scale (NRS), Behavioral Rating Scale for Dementia (BRSD), Neuropsychiatric Inventory (NPI), Neuropsychiatric Inventory-Clinician (NPI-C), Free and Cued Selective Recall Reminding Test (FCSRT), visual short term memory (VSTM), b-amyloid protein peptides (Ab), ß-amyloid 1-42 (Aß42), cerebro spinal fluid (CSF), total tau (T-tau), phosphorylated tau at threonine 181 (P-tau), computed tomography $(\mathrm{CT})$, magnetic resonace image (MRI), single photon emission tomography (SPECT), positron emission tomography (PET), (fluorodeoxyglucose) FDG, apolipoprotein E (APOE), Cathepsin D (CATD), Genetic Testing (GT), Posterior cortical atrophy (PCA), semantic dementia (SD), Primary progressive aphasia (PPA), Leisure-time physical activity (LTPA)

Authors' roles: CD, PPL, SH, DMC, JLC, CS, LL, VG and FT were involved in data collection and writing assistance. All authors have read and approved the final manuscript.

Acknowledgements and grants: The authors acknowledge the grant from the National Council of Scientific and Technical Research (CONICET) and the Rene Baron Foundation of the CEMIC University Institute, all of them from Argentina, to support this research.

Conflict of interests: The authors declare no conflict of interest.

\section{REFERENCES:}

1. Jack CR, Albert M, Knopman DS, et al. Introduction to Revised Criteria for the Diagnosis of Alzheimer's Disease: National Institute on Aging and the Alzheimer Association Workgroups. Alzheimer's \& dementia: The Journal of the Alzheimer's Association 2011, 7(3):257-262.

2. Albert MS, DeKosky ST, Dickson D, Dubois B, Feldman HH, Fox NC, Gamst A, Holtzman DM, Jagust WJ, Petersen RC, Snyder PJ, Carrillo MC, Thies B, Phelps CH. The diagnosis of mild cognitive impairment due to Alzheimer's disease: recommendations from the National Institute on Aging-Alzheimer's Association workgroups on diagnostic guidelines for Alzheimer's disease. Alzheimers Dement 2011, May; 7(3):270-9. 
3. Dillon C, Serrano CM, Castro D, Leguizamón PP, Heisecke SL, Taragano FE. Behavioral symptoms related to cognitive impairment. Neuropsychiatr Dis Treat 2013, 9:1443-55.

4. Ismail Z, Smith EE, Geda et al. Neuropsychiatric symptoms as early manifestations of emergent dementia: Provisional diagnostic criteria for mild behavioral impairment. Alzheimers Dement 2016, Feb; 12(2):195-202.

5. Taragano FE, Allegri RF, Krupitzki H, Sarasola DR, Serrano CM, Loñ L, Lyketsos CG. Mild behavioral impairment and risk of dementia: a prospective cohort study of 358 patients. J Clin Psychiatry 2009, Apr; 70(4):584-92.

6. Hallikainen I, Koivisto AM, Paajanen T, et al. Cognitive and neuropsychiatric symptom differences in early stages of Alzheimer's disease: Kuopio ALSOVE study. Dementia Geriatr Cogn Dis Extra 2012,2:209-218.

7. Burns A, Iliffe S. Alzheimer's disease. BMJ 2009, 338:b158.

8. Ballard, Clive et al. Alzheimer's disease. The Lancet 2011, (9770):1019-1031.

9. Jonsson T, Atwal JK, Steinberg S, Snaedal J, Jonsson PV, Bjornsson S, Stefansson H, Sulem P, Gudbjartsson D, Maloney J, Hoyte K, Gustafson A, Liu Y, Lu Y, Bhangale T, Graham RR, Huttenlocher J, Bjornsdottir G, Andreassen OA, Jönsson EG, Palotie A, Behrens TW, Magnusson OT, Kong A, Thorsteinsdottir U, Watts RJ, Stefansson K. A mutation in APP protects against Alzheimer's disease and age-related cognitive decline. Nature. 2012 Aug 2;488(7409):96-9.

10. Solomon A, Kivipelto M, Soininen H. Prevention of Alzheimer's disease: moving backward through the lifespan. J Alzheimers Dis 2013, 33 Suppl 1:S465-9.

11. Maximiliano Smietniansky, Bruno R. Boietti, Mariela A. Cal, María E. Riggi, Giselle P.Fuccile, Luis A. Camera, Gabriel D. WaismanImpact of Physical Activity on Frailty Status and How to Start a Semiological Approach to Muscular System AIMS Medical Science 2016, 3(1):52-60.

12. Tyler C. Smith, Besa Smith Consistency in Physical Activity and Increase in Mental Health in Elerly over a Decade: Are We Achieving Better Population Health. AIMS Medical Science 2016, 3(1):147-161.

13. Filipin F, Feldman M, Taragano FM, Martelli M, Sánchez V, García V, Tufro G, Heisecke S, Serrano S, Dillon C. The Efficacy of Cognitive Stimulation on Depression and Cognition in Elderly Patients with Cognitive Impairment: A Retrospective Cohort Study. AIMS Medical Science 2016, 3(1):1-14.

14. Reisberg B, Borenstein J, Salob SP, Ferris SH, Franssen E, Georgotas A. Behavioral symptoms in Alzheimer's disease: phenomenology and treatment. J Clin Psychiatry 1987,48 (Suppl):9-15.

15. Levin HS, High WM, Goethe K, et al. The neurobehavioral rating scale: assessment of the behavioral sequelae of head injury by the clinician. J Neurol Neurosurg Psychiatry 1987,50(2):183-193.

16. Rosen WG, Mohs RC, Davis KL. A new rating scale for Alzheimer's disease. Am J Psychiatry 1984,141(11):1356-1364. 
17. Cummings JL, Mega M, Gray K, Rosenberg-Thompson S, Carusi DA, Gornbein J. The Neuropsychiatric Inventory: comprehensive assessment of psychopathology in dementia. Neurology 1994,44(12):2308-2314.

18. de Medeiros K, Robert P, Gauthier S, et al. The Neuropsychiatric Inventory-Clinician rating scale (NPI-C): reliability and validity of a revised assessment of neuropsychiatric symptoms in dementia. Int Psychogeriatr 2010,22(6):984-994.

19. Lyketsos CG, Carrillo MC, Ryan JM, et al. Neuropsychiatric symptoms in Alzheimer's disease. Alzheimers Dement 2011,7(5):532-539.

20. Hamilton M. A rating scale for depression. Neurol Neurosurg Psychiatry 1960,23:5662.

21. Alexopoulos GS, Abrams RC, Young RC, Shamoian CS. Cornell scale for depression in dementia. Biol Psychiatry 1988;23(3):271-284.

22. Yesavage JA, Brink TL, Rose TL, et al. Development and validation of a geriatric depression screening scale: a preliminary report. J Psychiatr Res 1982-1983, 17(1):3749.

23. Cohen-Mansfield J, Marx MS, Rosenthal AS. A description of agitation in a nursing home. J Gerontol 1989,44(3):77-84.

24. Bastin C, Salmon E. Early neuropsychological detection of Alzheimer's disease. Eur J Clin Nutr 2014 Nov,68(11):1192-9.

25. Salmon, DP. Disorders of memory in Alzheimer's disease. In: Cermak, LS., editor. Handbook of Neuropsychology, Vol 2: Memory and Its Disorders. 2nd. Amsterdam: Elsevier 2000. p.155-95.

26. Gainotti G, Quaranta D, Vita MG, Marra C. Neuropsychological predictors of conversion from mild cognitive impairment to Alzheimer's disease. J Alzheimers Dis 2014;38(3):481-95.

27. Serrano CM, Dillon C, Leis A, Taragano FE, Allegri RF. Mild cognitive impairment: risk of dementia according to subtypes. Actas Esp Psiquiatr 2013 Nov-Dec,41(6):330-9.

28. Salmon DP, Bondi MW. Neuropsychological assessment of dementia. Annu Rev Psychol 2009,60:257-82.

29. Wagner M, Wolf S, Reischies FM, Daerr M, Wolfsgruber S, Jessen F, Popp J,Maier W, Hüll M, Frölich L, Hampel H, Perneczky R, Peters O, Jahn H, Luckhaus C, Gertz HJ, Schröder J, PantelJ, Lewczuk P, Kornhuber J, Wiltfang J. Biomarker validation of a cued recall memory deficit in prodromal Alzheimer disease. Neurology 2012 Feb 7,78(6):379-86.

30. Dubois B, Feldman HH, Jacova C, Hampel H, Molinuevo JL, Blennow K, DeKosky ST,Gauthier S, Selkoe D, Bateman R, Cappa S, Crutch S, Engelborghs S, Frisoni GB,Fox NC, Galasko D, Habert MO, Jicha GA, Nordberg A, Pasquier F, Rabinovici G, Robert P, Rowe C, Salloway S, Sarazin M, Epelbaum S, de Souza LC, Vellas B, Visser PJ, Schneider L, Stern Y, Scheltens P, Cummings JL. Advancing research diagnostic criteria for Alzheimer's disease: the IWG-2 criteria. Lancet Neurol 2014 Jun,13(6):61429. 
31. Koric L, Ranjeva JP, Felician O, Guye M, de Anna F, Soulier E, Didic M, Ceccaldi M. Cued recall measure predicts the progression of gray matter atrophyin patients with amnesic mild cognitive impairment. Dement Geriatr Cogn Disord 2013,36(3-4):197210.

32. Pietto M, , Parra MA, Trujillo N, Flores F, García AM, Bustin J, Richly P, ManesF, Lopera F, Ibáñez A, Baez S. Behavioral and Electrophysiological Correlates of Memory Binding Deficits in Patients at Different Risk Levels for Alzheimer's Disease. J Alzheimers Dis 2016 Jun 30,53(4):1325-40.

33. Dillon C, Allegri RF. Disinhibition in psychogeriatry: differential diagnosis with frontotemporal dementia. Vertex 2010 May-Jun;21(91):301-13.

34. Braak H, Braak E, Yilmazer D, de Vos RA, Jansen EN, Bohl J. Pattern of brain destruction in Parkinson's and Alzheimer's diseases. J Neural Transm (Vienna). 1996,103(4):455-90.

35. Braak H, Braak E. Neuropathological staging of Alzheimer-related changes. Acta Neuropathol (Berl) 1991, 82: 239-59.

36. Ribeiro, FM; Et al. Animal models of neurodegenerative diseases. Rev. Bras. Psiquiatr 2013, vol.35, suppl.2, pp.S82-S91.

37. Van Dam D, De Deyn PP. Animal models in the drug discovery pipeline for Alzheimer's disease. Br J Pharmacol 2011,164:1285-300.

38. Shaw LM, Vanderstichele H, Knapik-Czajka M, Clark CM, Aisen PS, Petersen RC, Blennow K, Soares H, Simon A, Lewczuk P, Dean R, Siemers E, Potter W, Lee VM, Trojanowski JQ; Alzheimer's Disease Neuroimaging Initiative. Cerebrospinal fluid biomarker signature in Alzheimer's disease neuroimaging initiative subjects. Ann Neurol. 2009 Apr,65(4):403-13.

39. Okonkwo OC. At the crossroads of preclinical AD and normal brain ageing. Lancet Neurol 2014 Oct,13(10):965-6.

40. Bouwman FH, Schoonenboom SN, van der Flier WM, van Elk EJ, Kok A, Barkhof F, Blankenstein MA, Scheltens P. CSF biomarkers and medial temporal lobe atrophy predict dementia in mild cognitive impairment. Neurobiol Aging 2007,28(7):10701074.

41. Mattsson N, Zetterberg H, Hansson O, Andreasen N, Parnetti L, Jonsson M, Herukka SK, van der Flier WM, Blankenstein MA, Ewers M, Rich K, Kaiser E, Verbeek M, Tsolaki M, Mulugeta E, Rosén E, Aarsland D, Visser PJ, Schröder J, Marcusson J, de Leon M, Hampel H, Scheltens P, Pirttilä T, Wallin A, Jönhagen ME, Minthon L, Winblad B, Blennow K. CSF biomarkers and incipient Alzheimer disease in patients with mild cognitive impairment. JAMA 2009,302(4):385-393.

42. Brys M, Pirraglia E, Rich K, Rolstad S, Mosconi L, Switalski R, Glodzik-Sobanska L, De Santi S, Zinkowski R, Mehta P, Pratico D, Saint Louis LA, Wallin A, Blennow K, de Leon MJ. Prediction and longitudinal study of CSF biomarkers in mild cognitive impairment. Neurobiol Aging 2009,30(5):682-690

43. Hampel H, Teipel SJ, Fuchsberger T, Andreasen N, Wiltfang J, Otto M, Shen Y, Dodel R, Du Y, Farlow M, Möller HJ, Blennow K, Buerger K. Value of CSF $\beta$ - 
amyloid1-42 and tau as predictors of Alzheimer's disease in patients with mild cognitive impairment. Mol Psychiatry 2004,9(7):705-710.

44. Hansson O, Zetterberg H, Buchhave P, Londos E, Blennow K, Minthon L. Association between CSF biomarkers and incipient Alzheimer's disease in patients with mild cognitive impairment: a follow-up study. Lancet Neurol 2006,5(3):228-234.

45. Hertze J, Minthon L, Zetterberg H, Vanmechelen E, Blennow K, Hansson O. Evaluation of CSF biomarkers as predictors of Alzheimer's disease: a clinical follow-up study of 4.7 years. J Alzheimers Dis 2010,21(4):1119-1128.

46. Herukka SK, Hallikainen M, Soininen H, Pirttilä T. CSF A $\beta 42$ and tau or phosphorylated tau and prediction of progressive mild cognitive impairment. Neurology 2005,64(7):1294-1297.

47. Riemenschneider M, Lautenschlager N, Wagenpfeil S, Diehl J, Drzezga A, Kurz A. Cerebrospinal fluid tau and $\beta$-amyloid 42 proteins identify Alzheimer disease in subjects with mild cognitive impairment. Arch Neurol 2002,59(11):1729-1734.

48. Shaw LM, Vanderstichele H, Knapik-Czajka M, Clark CM, Aisen PS, Petersen RC, Blennow K, Soares H, Simon A, Lewczuk P, Dean R, Siemers E, Potter W, Lee VM, Trojanowski JQ.Alzheimer's Disease Neuroimaging Initiative. Cerebrospinal fluid biomarker signature in Alzheimer's disease neuroimaging initiative subjects. Ann Neurol 2009,65(4):403-413

49. Visser PJ, Verhey F, Knol DL, Scheltens P, Wahlund LO, Freund-Levi Y, Tsolaki M, Minthon L, Wallin AK, Hampel H, Bürger K, Pirttila T, Soininen H, Rikkert MO, Verbeek MM, Spiru L, Blennow K. Prevalence and prognostic value of CSF markers of Alzheimer's disease pathology in patients with subjective cognitive impairment or mild cognitive impairment in the DESCRIPA study: a prospective cohort study. Lancet Neurol 2009 Jul,8(7):619-27.

50. Buchhave $\mathrm{P}$, Minthon L, Zetterberg $\mathrm{H}$, Wallin AK, Blennow $\mathrm{K}$, Hansson O. Cerebrospinal fluid levels of $\beta$-amyloid 1-42, but not of tau, are fully changed already 5 to 10 years before the onset of Alzheimer dementia. Arch Gen Psychiatry 2012 Jan,69(1):98-106.

51. Varghese T, Sheelakumari R, James JS, Mathuranath P. A review of neuroimaging biomarkers of Alzheimer's disease. Neurology Asia 2013, 18(3):239-248.

52. Filippi M, Agosta F, Barkhof F, Dubois B, Fox NC, Frisoni GB, Jack CR, Johannsen P, Miller BL, Nestor PJ, Scheltens P, Sorbi S, Teipel S, Thompson PM,Wahlund LO; European Federation of the Neurologic Societies. EFNS task force: the use of neuroimaging in the diagnosis of dementia. Eur J Neurol 2012 Dec, 19(12):e131-40, 1487-501.

53. Sperling RA, Aisen PS, Beckett LA, Bennett DA, Craft S, Fagan AM, Iwatsubo T, Jack CR Jr, Kaye J, Montine TJ, Park DC, Reiman EM, Rowe CC, Siemers E, Stern Y, Yaffe K, Carrillo MC, Thies B, Morrison-Bogorad M, Wagster MV, Phelps CH. Toward defining the preclinical stages of Alzheimer's disease: recommendations from the National Institute on Aging-Alzheimer's Association workgroups on diagnostic guidelines for Alzheimer's disease. Alzheimers Dement 2011 May,7(3):280-92. 
54. Frisoni GB, Fox NC, Clifford R, Jack CR Jr, Scheltens P, Thompson PM. The clinical use of structural MRI in AD. Nat Rev Neurol 2010, 6(2):67-77.

55. Teipel SJ, Meindl T, Grinberg L, Heinsen H, Hampel H. Novel MRI techniques in the assessment of dementia. Eur J Nucl Med Mol Imaging 2008 Mar,35 Suppl 1: S58-69.

56. Braskie MN, Thompson PM. A focus on structural brain imaging in the Alzheimer's disease neuroimaging initiative. Biol Psychiatry 2014 Apr 1,75(7):527-33.

57. Jack CR, Petersen RC, Xu YC, et al. Prediction of AD with MRI-based hippocampal volume in mild cognitive impairment. Neurology 1999, 52:1397-1403.

58. Visser PJ, Scheltens P, Verhey FRJ, et al. Medial temporal lobe atrophy and memory dysfunction as predictors for dementia in subjects with mild cognitive impairment. J Neurol 1999, 246:477-485.

59. Petersen RC, Jack CR, Xu YC, et al. Memory and MRI-based hippocampal volumes in aging and AD. Neurology 2000, 54:581 +587 .

60. Golebiowski M, Barcikowska M, Pfeffer A. Magnetic resonance imaging-based hippocampal volumetry in patients with dementia of the Alzheimer type. DementGeriatrCognDisord 1999, 10:284-288.

61. Frisoni GB, Laakso MP, Beltramello A, et al. Hippocampal and entorhinal cortex atrophy in frontotemporal dementia and Alzheimer's disease. Neurology 1999, 52:91100.

62. Pantel J, Schroder J, Jauss M, et al. Topography of callosal atrophy reflects distribution of regional cerebral volume reduction in Alzheimer's disease. Psychiatry Res 1999,90:181-192.

63. De León MJ, Convit A, Wolf OT, Tarshish CY, DeSanti S, Rusinek H, et al. Prediction of cognitive decline in normal elderly subjects with 2-[(18)F]fluoro-2-deoxy-Dglucose/poitron-emission tomography (FDG/PET). Proc Natl Acad Sci USA 2001; 98 : 10966-71.

64. Brun A, Englund E. Brain changes in dementia of Alzheimer's type relevant to new imaging diagnostic methods. ProgNeuroPsychopharmacolBiolPsychiat 1986, 10: 297 308.

65. Migneco O, Benoit M, Koulibaly PM, et al. Perfusion brain SPECT and statistical parametric mapping analysis indicate that apathy is a cingulate syndrome: a study in Alzheimer's disease and nondemented patients. NeuroImage 2001, 13:896-902.

66. Woodard JL, Grafton ST, Votaw JR, Green RC, Dobraski ME, Hoffman JM. Compensatory recruitment of neural resources during overt rehearsal of word lists in Alzheimer's disease. Neuropsychology 1998, 12: 491-504.

67. Small SA, Perera GM, DeLaPaz R, Mayeux R, Stern Y. Differential regional dysfunction of the hippocampal formation among elderly with memory decline and Alzheimer's disease. Ann Neurol 1999, 45: 466-72.

68. Rose SE, Chen F, Chalk JB, Zelaya FO, Strugnell WE, Benson M, Semple J, Doddrell DM. Loss of connectivity in Alzheimer's disease: an evaluation of white matter tract integrity with colour coded MR diffuion tensor imaging. J NeurolNeurosurg Psychiatry 2000, 69:528-530. 
69. Klunk WE, Engler H, Nordberg A, Wang Y, Blomqvist G, Holt DP, et al. Imaging brain amyloid in Alzheimer's disease with Pittsburgh Compound-B. Ann Neurol 2004, 55: 306-19.

70. Mosconi L, Tsui WH, Pupi A, De Santi S, Drzezga A, Minoshima S, de Leon MJ. (18)F-FDG PET database of longitudinally confirmed healthy elderly individuals improves detection of mild cognitive impairment and Alzheimer's disease. J NuclMed 2007 Jul, 48(7):1129-34.

71. McMurtray AM, Licht E, Yeo T, Krisztal E, Saul RE, Mendez MF. Positron emission tomography facilitates diagnosis of early-onset Alzheimer's disease. Eur Neurol 2008, 59(1-2):31-7.

72. Förster S, Grimmer T, Miederer I, Henriksen G, Yousefi BH, Graner P, Wester HJ, Förstl H, Kurz A, Dickerson BC, Bartenstein P, Drzezga A. Regional expansion of hypometabolism in Alzheimer's disease follows amyloid deposition with temporal delay. Biol Psychiatry 2012 May, 1;71(9):792-7.

73. Jagust W, Thisted R, Devous MD Sr, Van Heertum R, Mayberg H, Jobst K, Smith AD, Borys N. SPECT perfusion imaging in the diagnosis of Alzheimer's disease: a clinicalpathologic study. Neurology 2001 Apr 10;56(7):950-6.

74. Schmidt D, Zimmermann R, Lewczuk P, Schaller G, Degirmenci U, KreilS,Wiltfang J, Kuwert T, Kornhuber J, Weih M. Confirmation rate of blinded(99m)Tc-SPECT compared to neurochemical dementia biomarkers in CSF in patients with Alzheimer disease. J Neural Transm 2010 Sep,117(9):1111-4.

75. O'Brien JT, Firbank MJ, Davison C, Barnett N, Bamford C, Donaldson C, Olsen K, Herholz K, Williams D, Lloyd J. 18F-FDG PET and perfusion SPECT in the diagnosis of Alzheimer and Lewy body dementias. J Nucl Med 2014 Dec, 55(12):1959-65.

76. Panegyres PK, Rogers JM, McCarthy M, Campbell A, Wu JS.Fluorodeoxyglucosepositron emission tomography in the differential diagnosis of early-onset dementia: a prospective, community-based study. BMC Neurol 2009 Aug 12;9:41.

77. Silverman DH, Truong CT, Kim SK, Chang CY, Chen W, Kowell AP, Cummings JL, Czernin J, Small GW, Phelps ME. Prognostic value of regional cerebral metabolism in patients undergoing dementia evaluation: comparison to a quantifying parameter of subsequent cognitive performance and to prognostic assessment without PET. MolGenetMetab 2003 Nov,80(3):350-5.

78. Anchisi D, Borroni B, Franceschi M, Kerrouche N, Kalbe E, Beuthien-Beumann B, Cappa S, Lenz O, Ludecke S, Marcone A, Mielke R, Ortelli P, Padovani A, Pelati O, Pupi A, Scarpini E, Weisenbach S, Herholz K, Salmon E, Holthoff V, Sorbi S, Fazio F, Perani D. Heterogeneity of brain glucose metabolism in mild cognitive impairment and clinical progression to Alzheimer disease. Arch Neurol 2005 Nov, 62(11):1728-33.

79. Klunk WE, Engler H, Nordberg A, Wang Y, Blomqvist G, Holt DP, Bergström M, Savitcheva I, Huang GF, Estrada S, Ausén B, Debnath ML, Barletta J, Price JC, Sandell J, Lopresti BJ, Wall A, Koivisto P, Antoni G, Mathis CA, Långström B. Imaging brain amyloid in Alzheimer's disease with Pittsburgh Compound-B. AnnNeurol 2004 Mar, 55(3):306-19. 
80. Wolk DA, Grachev ID, Buckley C, Kazi H, Grady MS, Trojanowski JQ, Hamilton RH, Sherwin P, McLain R, Arnold SE. Association between in vivo fluorine 18labeledflutemetamol amyloid positron emission tomography imaging and in vivo cerebralcortical histopathology. Arch Neurol 2011 Nov, 68(11):1398-403.

81. Clark CM, Pontecorvo MJ, Beach TG, Bedell BJ, Coleman RE, Doraiswamy PM, Fleisher AS, Reiman EM, Sabbagh MN, Sadowsky CH, Schneider JA, Arora A, Carpenter AP, Flitter ML, Joshi AD, Krautkramer MJ, Lu M, Mintun MA, Skovronsky DM; AV-45-A16 Study Group. Cerebral PET with florbetapir compared with neuropathologyat autopsy for detection of neuritic amyloid- $\beta$ plaques: a prospective cohortstudy. Lancet Neurol 2012 Aug, 11(8):669-78.

82. Rowe CC, Ackerman U, Browne W, Mulligan R, Pike KL, O'Keefe G, TochonDanguyH, Chan G, Berlangieri SU, Jones G, Dickinson-Rowe KL, Kung HP, Zhang W, Kung MP,Skovronsky D, Dyrks T, Holl G, Krause S, Friebe M, Lehman L, LindemannS, Dinkelborg LM, Masters CL, Villemagne VL. Imaging of amyloid beta in Alzheimer's disease with 18F-BAY94-9172, a novel PET tracer: proof of mechanism. Lancet Neurol. 2008 Feb,7(2):129-35.

83. Curtis C, Gamez JE, Singh U, Sadowsky CH, Villena T, Sabbagh MN, Beach TG,Duara R, Fleisher AS, Frey KA, Walker Z, Hunjan A, Holmes C, Escovar YM, Vera CX,Agronin ME, Ross J, Bozoki A, Akinola M, Shi J, Vandenberghe R, IkonomovicMD,Sherwin PF, Grachev ID, Farrar G, Smith AP, Buckley CJ, McLain R, Salloway S. Phase 3 trial of flutemetamol labeled with radioactive fluorine 18 imaging andneuritic plaque density. JAMA Neurol 2015 Mar7,2(3):287-94.

84. Leinonen V, Alafuzoff I, Aalto S, Suotunen T, Savolainen S, Någren K, Tapiola T, Pirttilä T, Rinne J, Jääskeläinen JE, Soininen H, Rinne JO. Assessment of beta-amyloid in a frontal cortical brain biopsy specimen and by positron emission tomography with carbon 11-labeled Pittsburgh Compound B. Arch Neurol 2008Oct, 65(10):1304-9.

85. Landau SM, Mintun MA, Joshi AD, Koeppe RA, Petersen RC, Aisen PS, Weiner MW, Jagust WJ; Alzheimer's Disease Neuroimaging Initiative. Amyloid deposition, hypometabolism, and longitudinal cognitive decline. Ann Neurol 2012 Oct, 72(4):57886.

86. Forsberg A, Engler H, Almkvist O, Blomquist G, Hagman G, Wall A, RingheimA, Långström B, Nordberg A. PET imaging of amyloid deposition in patients with mild cognitive impairment. Neurobiol Aging 2008 Oct,29(10):1456-65.

87. Koivunen J, Scheinin N, Virta JR, Aalto S, Vahlberg T, Någren K, HelinS,Parkkola R, Viitanen M, Rinne JO. Amyloid PET imaging in patients with mild cognitive impairment: a 2-year follow-up study. Neurology 2011 Mar 22, 76(12):1085-90.

88. Johnson KA, Minoshima S, Bohnen NI, Donohoe KJ, Foster NL, Herscovitch P, Karlawish JH, Rowe CC, Carrillo MC, Hartley DM, Hedrick S, Pappas V, Thies WH; Appropriate use criteria for amyloid PET: a report of the Amyloid Imaging Task Force, the Society of Nuclear Medicine and Molecular Imaging, and the Alzheimer's Association. Alzheimer's Association; Society of Nuclear Medicine and Molecular Imaging; Amyloid Imaging Taskforce. Alzheimers Dement, 2013 Jan,9(1):e-1-16. 
89. Pérez-Tur J. La genética y la EA. Rev Neurol 2000, 30:161-9.

90. Valls-Pedret C, Molinuevo JL, Rami L. Diagnóstico precoz de la EA: fase prodrómica y preclínica. Rev Neurol 2010, 51: 471-80.

91. Corder EH, Saunders AM, Strittmatter WJ, et al. Gene dose of apolipoprotein E type E4 allele and the risk of Alzheimer's disease in late onset families. Science 1993,261: 921 3.

92. Yoshizawa T, Yamakawa-Kobayashi K, Komatsuzaki Y, et al. Dose-dependent association of apolipoprotein E allele epsilon 4 with late-onset, sporadic Alzheimer's disease. Ann Neurol 1994, 36: 656-9.

93. Blacker D, Tanzi RE. The genetics of Alzheimer disease. ArchNeurol 1998,55:294-6.

94. Lopera F. Formas Hereditarias de la Demencias. En: Mangone CA, Allegri FR, Zrizaga RL. Demencia, enfoque multidiscipilnario. Ediciones Sagitario, 1997. 255-270.

95. Tilvis RS,Strandberg TE,Juva K. Apolipoprotein E phenotypes,dementiaand mortality in a prospective population sample. J Am Geriatr Soc1998, 46:712-5.

96. Kukull WA, Schellenberg GD, Bowen JD. Apolipoprotein E in Alzheimer 's disease: risk and case detection. A case-control study. J Clin Epidemiol 1996, 49:1143-8.

97. Papassootiropoulos A, Bagli M, Kurz A. A genetic variation of cathepsin D is a major risk factor for Alzheimer s disease. Ann Neurol 2000,47(3):399-403.

98. Suárez-González A1, Henley SM2, Walton J2, Crutch SJ2 Posterior cortical atrophy: an atypical variant of Alzheimer disease. Psychiatr Clin North Am. 2015 Jun;38(2):211-20.

99. Aygün D, Güngör IL. Why is Alzheimer disease confused with other dementias? Turk J Med Sci. 2015;45(5):1010-4.

100. Serrano CM, Dillon C, Castro DM, Iturry M, Rojas GJ, Bartoloni L, Taragano F, Allegri RF. Neuropsychiatric symptoms in primary progressive aphasia. Rev Neurol. 2010 Jan 1-15;50(1):58-9.

101. Mesulam MM1, Rogalski EJ1, Wieneke C1, Hurley RS1, Geula C1, Bigio EH2, Thompson CK3, Weintraub S1. Primary progressive aphasia and the evolving neurology of the language network. Nat Rev Neurol. 2014 Oct;10(10):554-69.

102. Taragano FE, Castro DM, Serrano CM, Heisecke SL, Pérez Leguizamón P, Loñ L, Dillon C. A survey on biomarkers and early diagnosis in Alzheimer's disease. Medicina 2015,75(5):282-8.

103. Carol Dillon, Fernando E. Taragano. Special Issue: Activity and Lifestyle Factors in the Elderly: Their Relationship with Degenerative Diseases and Depression. AIMS Medical Science, 2016, 3(2): 213-216.

104. Martha Clare Morris Nutrition and risk of dementia: overview and methodological issues. Ann N Y Acad Sci 2016 Mar,1367(1):31-7.

105. Crichton GE, Elias MF, Alkerwi A. Chocolate intake is associated with better cognitive function: The Maine-Syracuse Longitudinal Study. Appetite 2016 May 1,100:126-32.

106. Mitchell, E. S., Slettenaar, M., van der Meer, N., Transler, C., Jans, L., Quadt, F., et al. Differential contributions of theobromine and caffeine on mood, psychomotor performance and blood pressure. Physiology \& Behavior 2011, 104, 816-822. 
107. Yoshimura, H. The potential of caffeine for functional modification from cortical synapses to neuron networks in the brain. Current Neuropharmacology 2005, 3, 309316.

108. Panza, F., Solfrizzi, V., Barulli, M. R., Bonfiglio, C., Guerra, V., Osella, A., et al. Coffee, tea, and caffeine consumption and prevention of late-life cognitive decline and dementia: a systematic review. Journal of Nutrition Health and Aging 2015,19, 313-328.

109. Morris, M.C. Nutritional determinants of cognitive aging and dementia. Proc. Nutr. Soc 2012, 71: 1-13.

110. Morris, M.C., D.A. Evans, J.L. Bienias, et al. Dietary folate and vitamin B12 intake and cognitive decline among community-dwelling older persons. Arch. Neurol 2005. 62: 641-645.

111. Morris, M.S., J. Selhub \& P.F. Jacques. Vitamin B-12 and folate status in relation to decline in scores on theminimental state examination in the framingham heart study. $\mathrm{J}$. Am. Geriatr. Soc 2012, 60: 1457-1464. 7.

112. Morris, M.S., P.F. Jacques, I.H. Rosenberg \& J. Selhub. Folate and vitamin B-12 status in relation to anemia, macrocytosis, and cognitive impairment in older Americans in the age of folic acid fortification.Am. J. Clin. Nutr 2007, 85: 193-200.

113. Keys A, Menotti A, Karvonen MJ, et al. The diet and 15-year death rate in the seven countries study. Am J Epidemiol 1986,124:903-15.

114. Sofi F. The Mediterranean diet revisited: evidence of its effectiveness grows. Curr Opin Cardiol 2009 Sep,24(5):442-6.

115. Rumawas ME, Dwyer JT, McKeown NM, Meigs JB, Rogers G, Jacques PF. The development of the Mediterranean-style dietary pattern score and its application to the American diet in the Framingham Offspring Cohort. J Nutr 2009,139:1150-6.

116. Bach A, Serra-Majem L, Carrasco JL, et al. The use of indexes evaluating the adherence to the Mediterranean diet in epidemiological studies: a review. Public Health Nutr 2006, 9:132-46.

117. Feart C, Samieri C, Rondeau V, et al. Adherence to a Mediterranean diet, cognitive decline, and risk of dementia. JAMA 2009,302:638-48.

118. Scarmeas N, Stern Y, Tang MX, Mayeux R, Luchsinger JA. Mediterranean diet and risk for Alzheimer's disease. Ann Neurol 2006, 59:912-21.

119. Van Dyk K, Sano M. The impact of nutrition on cognition in the elderly. Neurochem Res 2007, 32:893-904.

120. Devore EE, Grodstein F, van Rooij FJ, et al. Dietary intake of fish and omega-3 fatty acids in relation to long-term dementia risk. Am J Clin Nutr 2009, 90:170-6.

121. Thaipisuttikul $P$, and Galvin JE. Use of medical foods and nutritional approaches in the treatment of Alzheimer's disease. Clin Pract (Lond) 2012 March, 9(2): 199-209. 